\title{
Outcome of girls with central precocious puberty (CPP)
}

\author{
Ruchi Shah", Sudha Rao, Meena Desai, Rajesh Joshi, Aparna Limaye, Ruchi Parikh, Poonam Singh, Neha Dighe \\ From 8th APPES Biennial Scientific Meeting \\ Darwin, Australia. 29 October - 1 November 2014
}

Due to non-affordability of GnRH analogues (GnRHa), Medroxy Progesterone Acetate (MPA) is still used as a treatment option in girls with CPP in India. The aim here is to study the clinical features of girls with CPP in respect to the age at presentation, etiology and outcome as per the medication used for their treatment ( $\mathrm{GnRHa}$ vs MPA).

Retrospective study of 38 girls with $\mathrm{CPP}$ (19 idiopathic) treated with either MPA or GnRHa (Luprorelin or Triptorelin) were followed up for period varying from 1 to 8 years. The progression of growth parameters in relation to their age, etiology and medication used for the treatment was studied. Statistical analysis was done using one way ANOVA, unpaired t-test and Pearson correlation tests.

Mean age at onset of puberty in girls with idiopathic $\operatorname{ICPP}(\mathrm{n}=19)$, neurogenic $\operatorname{NCPP}(\mathrm{n}=12)$ and hypothalamic hamartoma $(\mathrm{HH})(\mathrm{n}=7)$ were $4.68 \pm 2.83,5.32 \pm 2.20$ and $1.76 \pm 1.44$ years, respectively(P 0.003). Mean height sds at presentation of all girls was higher $(0.51 \pm 1.80)$ with comparison to $\mathrm{MPH}$ sds $(0.90 \pm 1.19)(\mathrm{P}=0.0021) .70 \%$ of the girls presented with SMR stage 3. Bone age was more advanced as compared to height age in all $(\mathrm{P}=0.0001)$ and this trend continued till last follow up. At presentation, girls with ICPP were significantly heavier and taller as compared to NCPP and HH $(\mathrm{P}=0.002$ for weight SDS and 0.022 for height SDS). Mean baseline $\mathrm{LH}, \mathrm{FSH}$ and estradiol were $3.05 \pm 2.49 \mathrm{mIU} / \mathrm{ml}$, $4.75 \pm 2.29 \mathrm{mIU} / \mathrm{ml}$ and $29.43 \mathrm{pg} / \mathrm{ml}$; respectively. At presentation, bone age was more advanced in $\mathrm{HH}(\mathrm{BA} / \mathrm{CA}$ $\mathrm{P}=0.0001$ with $\mathrm{BA} / \mathrm{HA} \mathrm{P}=0.03)$ and $\mathrm{LH}$ levels significantly higher(5.6 $\pm 2.26 ; \mathrm{P}=0.02)$. At last follow up, there was no significant difference in weight $\mathrm{sds}(\mathrm{p}=0.285)$, height $\mathrm{sds}(\mathrm{p}=0.074)$ and PAH $\mathrm{sds}(\mathrm{p}=0.056)$ in girls of different age groups and etiologies. After 4 years of

Division of Pediatric Endocrinology, Bai Jerbai Wadia Hospital for Children, Mumbai, Maharashtra, India 